\title{
Drawing
}

\section{A Moment of Peace: An Artistic Representation of the Influence of Healthcare on Social Disruption}

Nafisa Choudhury ${ }^{1}$

\section{Abstract}

\section{Description}

This original pen-and-ink artwork features a lily on the water symbolizing peace. As war, distrust, chaos and coups wreak havoc throughout many developing nations, healthcare workers and public health officials should be encouraged that we do in fact have a part to play in managing the human health affected by the disruption. Health work can provide a zone of comfort, spread solidarity and understanding, and manage the human toll of war. Healthcare workers have major roles in peace-keeping efforts as a result of these determinations and their impact on peace should be acknowledged and lauded. We hope that as we move forward, we can continue to improve and create positive healthcare outcomes through our public health and social work initiatives.

\section{Keywords}

medicine in the arts; health personnel; peace; healthcare; public health; solidarity; art; artwork; humanities; lily; war; drawing

\section{Acknowledgments}

With great regard and recommendation to MacQueen G, Santa-Barbara J. Peace building through health initiatives. BMJ. 2000;321(7256):293-296. https://doi.org/10.1136/ $\underline{\text { bmj.321.7256.293 }}$

\section{Conflicts of Interest}

The author declares she has no conflicts of interest.

\section{Author Affiliation}

1. Dr. Kiran C. Patel College of Allopathic Medicine, Nova Southeastern University

Author affiliations are listed at the end of this article.

Correspondence to: Nafisa Choudhury 7085 Nova Dr., Apt 308 Davie, FL 33317 (nc1083@mynsu.nova.edu) 
HCA Healthcare Journal of Medicine

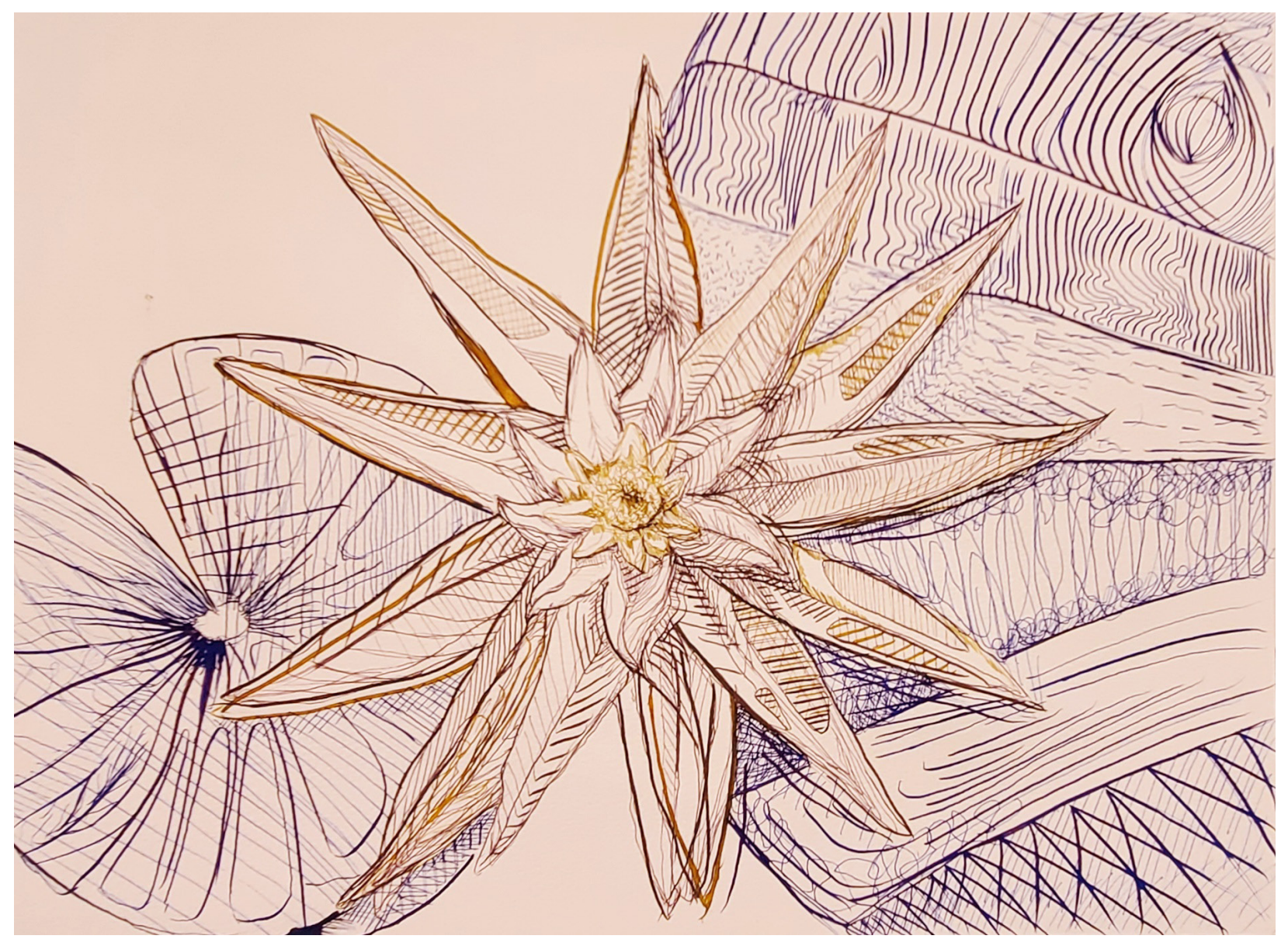

